INTERNATIONAL JOURNAL OF

MULTIDISCIPLINARY STUDIES IN ARCHITECTURE

AND CULTURAL HERITAGE

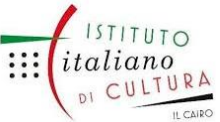

\title{
Revitalizing Cultural Heritage Through Building Information Modeling (BIM)
}

\author{
Yasmine Sabry Mahmoud a, *
}

a Lecturer, Architectural Department, Zagazig University, Sharqia, Egypt

\begin{abstract}
The paper will discuss using Building Information Modelling BIM as an efficient tool of conservation and museums management, specifically in revitalizing the museum of Islamic arts in Cairo after it had been attacked by terrorists as this museum was conserved before and opened to the public 2010, case study method of research chosen to highlight the most important way to deal with heritage at crisis time when every minute differ in saving an object or the saving the building itself, the project was done as a fast track project, as it depended on BIM to achieve the three aspects of good project management which are time, cost and quality. From the research findings that using BIM can save time of implementation and technical documents producing up to $20 \%$ of the time needed for the same scope, so it compare between 2010 and 2014 versions of management to observe what is the impact of using BIM on the revitalization of the museum.

Keywords

- BIM

- $\quad$ Heritage Crisis.

- $\quad$ Islamic Museum.

- $\quad$ Management.

- Revitalization
\end{abstract}

\section{Research Methodology}

A case study approach was chosen as a strategy which combines experimental and simulation research to be developed throughout the project. The experiment explored many variables in the different phases of design development which helped in taking design-related decisions. The museum exhibition design was reviewed to be more secured while seeking revitalization solutions and simulating how the building and exhibition will be like after completion. This was achieved using a Revit model in the early redesign stage and a complete Building Information Modeling system during the levels of the fourth and fifth dimensions of BIM, where the fourth is time scheduling and the fifth is cost estimation.

\section{Research Hypothesis}

Developing a heritage building after a crisis using Building Information Modeling offers better management for the process than the case when not using BIM.

\section{Research Objectives}


INTERNATIONAL JOURNAL OF

MULTIDISCIPLINARY STUDIES IN ARCHITECTURE

AND CULTURAL HERITAGE

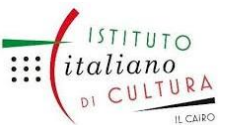

Achieve an efficient management plan for heritage projects via Building Information Modeling, especially in a time of crisis when management gets much more complicated than during ordinary circumstances.

\section{Introduction}

On the 24th of January 2014, terrorists attacked the museum during their attack on The Cairo Police Security Centre which is located right in front of the museum. This caused a complete collapse of the museum interiors in addition to some objects made of weak materials getting completely destroyed, whereas those made of hard materials like iron, marble, wood, and stone have survived. As a reaction to this crisis, many procedures were taken to secure the collections which have become under the debris through a very sensitive process of collections saving. Conservation and exhibition revitalization was strongly needed to save both the historic building and the collections and so in 2015, The United Arab Emirates funded this revitalization project and asked the authorities for a complete management plan. This is where building information modelling can be used in crisis management; offering a more effective solution of management.

This museum was established by Khedive Ismail when the number of objects displayed at El Hakim Mosque increased and the space was very tight. The idea of establishing a museum of Islamic arts showed up and a new building was constructed in the area of Bab El Khalq in Cairo, Egypt. The construction started in 1899 and was completed in 1902. The building was named The Arab antiquities house back then, but after the collections increased and was coming from all over the world, the "Arab" term didn't suit the museum anymore and so it was changed into The Museum of Islamic Arts.

The most recent development project prior to this one was between the years 2002 and 2010 and the building conservation procedures were implemented by Egyptian engineers under the supervision of The Supreme Council of Antiquities, whereas the museum display was set by a French interior designer.

The historic development of creating architectural drawings started in 2 dimensions (2D) then the platform of engineering software programs progressed to 3D way to BIM. BIM is generally defined as "a simulation of construction in a virtual environment by constructing a model that contains all building information"i. BIM doesn't merely present a 3D model but rather has many more dimensions added to the original model; as followsii:

\subsection{Dimensions before BIM}

First dimension: drafting (scratch stage)

Second dimension: vector drawing views and plans

Third dimension: forming the model with tools such as laser scan 
INTERNATIONAL JOURNAL OF

MULTIDISCIPLINARY STUDIES IN ARCHITECTURE

AND CULTURAL HERITAGE

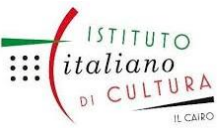

ISSN: $2735-4415$

VOLUME 1, ISSUE 2, 2018, $34-52$.

www.egyptfuture.org/ojs/

\subsection{Dimensions after BIM}

Fourth dimension: time scheduling; i.e. the connection between timing information and the construction progress

Fifth dimension: cost estimation and value engineering Sixth dimension: applying sustainability measures

Seventh dimension: facility management and the building lifecycle Eighth dimension: accident prevention

The fourth and fifth dimensions are fulfilled in this paper through the limit commitment mode (LCM) which enables putting some items on hold in order to focus on all the primary items of the revitalization project instead; which enables improving the creativity of the design

projectiii. The LCM approach was already applied through the experimental part of this research.

\section{Research Question}

Does BIM have a better impact on managing heritage projects after crisis occurrence than when using the separate packages of modeling and scheduling?

6. Why was The Islamic Museum taken as a case study?

The Islamic Museum was chosen as a case study as it illustrates the case of sudden crisis for the first time in Egypt. A monument faces an explosion by a terrorist attack, so the case is a unique example and it will clarify the role of BIM as it can establish cause and effect in a real settingiv. The museum as a case study has the following aspects which make it a suitable case for this research:

- $\quad$ Crisis events are known and the impact on the rich materials is very clear in showing the crisis effect on the building interiors and exhibition

- Work implementation steps and the platform of software programs can be arranged chronologically according to the events

- $\quad$ The case study focuses on a group of factors that formulate better perception of the role of modeling in managing the project

- $\quad$ The museum case is challenging and considered a strong case due to its many variables and the changes to be applied with response to emerging suggestions, especially which the change in variables order which wasn't planned before

Most of the data can be represented by implementation items in BIM 


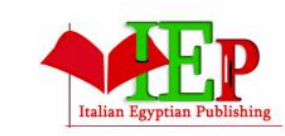

ISSN: $2735-4415$
INTERNATIONAL JOURNAL OF

MULTIDISCIPLINARY STUDIES IN ARCHITECTURE

AND CULTURAL HERITAGE

VOLUME 1, ISSUE 2, 2018, $34-52$.

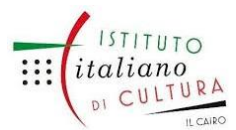

www.egyptfuture.org/ojs/

- $\quad$ The same scope was done before at 2010 without BIM so measuring its effect will be very clear more than comparing the BIM case of Islamic museum with other building

\section{Data collecting criteria}

Data was collected directly from the site using electronic distance meters such as: 3D Laser Scan and Total Station, then further information was gathered from the owner of the project and from the contractor as well, so that every piece of information came from a trusted source. The data was digitized then via both Autodesk AutoCAD and Revit for the purpose of creating BIM. Navisworks was also used to merge the time and cost schedules done via primavera with the Revit model. The electronic version of the information and the drawings as well as the hard copy sources were all used in this research to ensure information reliability.

\section{Limits on collected data}

The data collected was limited to the museum building without including the garden or the administrative building in order to focus on the building of the heritage monument and the exhibited collections. The model created through BIM reflected mainly general headlines of time scheme and the items included in the bill of quantities. The model is represented within level of development 400 (LOD) which shows the actual fabrication features through the model where elements are graphically represented in terms of size, shape, location, quantity and orientation with detailing, fabrication, assembly and installation information $v$. The LOD designed by The American Institute for Architects (AIA) reflects the progress of the work while being linked to time and cost (4th and 5th dimensions in BIM)vi. The level of detail used in this model is between $\mathrm{G} 2$ and $\mathrm{G} 3$, which shows further details of the development process, see Fig. 1.

\section{LEVEL of DEVELOPMENT

LOD 100 LOD $200 \quad$ LOD 300
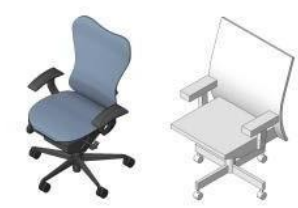

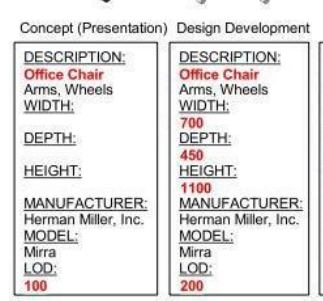

(Only data in red is useable)
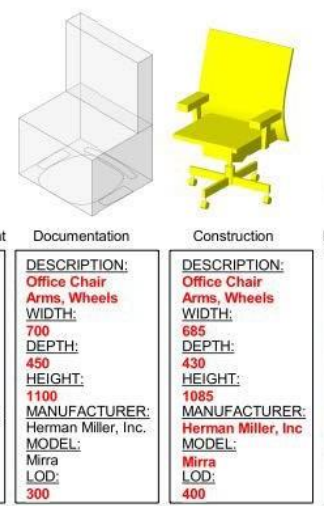

$\frac{M}{30}$
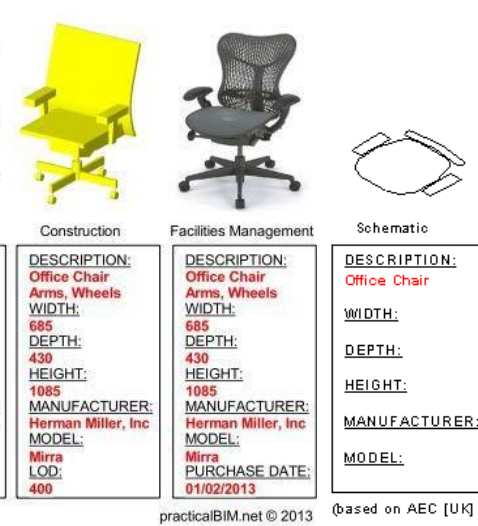

DESCRIPTION:
OfIICE Chair
MIDTH:
DEPTH:
HEIGHT:
MANUFACTURER:
MODEL:

practicalBIM.net $\odot 2013$

\section{LEVEL of DETAIL}

G0 G1 G2
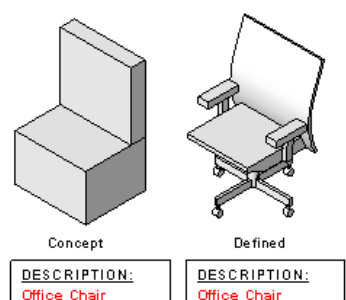

Office Chair

MOIDTH:
700
DEPTH:

DEPTH:
450
HEIGHT:

1100 MANUFACTURER:

MODEL:

Fig. 1. Levels of development and levels of detail 
INTERNATIONAL JOURNAL OF

MULTIDISCIPLINARY STUDIES IN ARCHITECTURE

AND CULTURAL HERITAGE

\section{Source: The implementation of BIM within the public procurement, Bobagni, Marzia, 2013}

\section{Platform of Supported Software Programsvii}

To create the museum model through BIM, some software programs and tools were used. In the stage of data collection, parts of the building were collected through a 3D Laser Scan while the other parts were collected by Total Station. All parts were exported through both AutoCAD and Revit family. These software programs, among others, formulate the platform of software programs used to build the museum model and arranged in order of use as follows:

- Cyclone: A software program used to formulate the points cloud by receiving the data from the building to the scanner and transferring it to the computer

- AutoCAD Cloud Works: A points cloud analyzer used to digitize the model through a CAD application

- Revit Cloud Works: A points cloud analyzer used to build up the model via the Revit family

- Primavera: A software for scheduling used to produce the time and cost tables

- Autodesk AutoCAD

- Revit: An Autodesk software tool for designers. The software allows users to produce Building Information Models and

corresponding 2D drawings, which are "snapshots" of the model, as well as access the building information from a model database

- Navisworks: An Autodesk software program that can be used to connect the Revit model to the primavera file to apply the fourth and fifth dimensions

10. Museum revitalization scope of work 
The revitalization work achieved was documented in the Bill Of Quantities. Accordingly, the B.O.Q was divided into the museum building, administrative building, museum garden, and control room. Each building was further categorized by work description such as; civil work, carpentry, marble, lighting, air conditioning, aluminum works, showcases, and security systems. All those works mentioned are relevant to the original items which were already existent in the museum before the explosion and were necessary to restore in order to bring back the original image of the museum. further details the for revitalization plan as follows:

1- Civil and architectural revitalization work of the museum building:

- Remove explosion waste and clear the space

- Install wooden protection boxes padded with sponge were over the hanging collections due to the difficulty in moving the objects

- Apply a gypsum layer upon plastic sheets to protect the marble flooring

- Re-apply plaster and gypsum ornaments on the walls due to total damage

- Maintain and re-paint metal doors and steel protection windows

- Remove and replace damaged aluminum windows

- Maintain and fix ceiling fiber beams

- Maintain and fix plumping work

- Maintain and fix escape stairs and exit passages

- Supply and install plain concrete to treat the flooring settlement

- Perform masonry work while rebuilding new counters

- Clean facades to remove all the dust which came from the explosion

2- Control room work (contains all that is relevant to the monitoring system and the cabling connecting the museum to the external control room) -Install a new suspended ceiling and a raised floor to include the cabling network 
INTERNATIONAL JOURNAL OF

MULTIDISCIPLINARY STUDIES IN ARCHITECTURE

AND CULTURAL HERITAGE

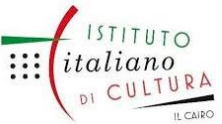

-Install a new bathroom inside the control room to separate the security's circulation from that of the visitors

-Supply and install a computer unit with operating programs to monitor the performance of security machines

3- Marble Work (cleaning and replacing works for the damaged marble):

- Supply and install marble floors of the same type that was used in the museum and which were partly damaged due to floor settlement

- Clad counters and create board signs carrying the name of the museum in Arabic and English to be placed on the counters.

4- Carpentry (supplying and installing the wooden features that were totally lost in the explosion):

- Supply and install main wooden door of the museum and internal doors that were totally lost

- Maintain paint on remaining doors

- Supply and install wooden windows

- Supply and install missing parts of the damaged handrail 5-Lighting (many fixtures were lost, partly damaged, or totally destroyed):

- Replace lost and destroyed pieces

- Supply and install new lighting fixtures

- Supply and install rails for lighting tracks

- Install new lighting outlets

- Maintain electric panel boards

- Maintain undamaged lighting fixtures 6-Mechanical Work:

- Review all the museum work in The AC system

- Maintain air Handling Units (A.H.U) and chiller machines

- Supply and install new air ducts 
- Maintain supply and return grills

- Maintain the handicapped elevator

- Maintain the electric generator

- Connect all systems to the control room and operate them

7- Showcases (since they were mostly made of glass so most of the old ones were destroyed and only a few survived; thus new pieces were fabricated with little changes to suit the new collections from 2015):

- Supply and install free standing showcases

- Fix wall showcases

- Maintain and supply accessories for table showcases

- Supply and install protection glass

- Maintain remaining showcases

8- Aluminum work (replacing damaged windows):

- Supply and install new aluminum windows

- Supply and install steel screens with mesh cloth to reduce the sun effect

9- Accessories (to fixate the objects and make a protection zone):

-Fix plexi supports of showcases

-Supply and install all accessories needed for museum display -Install a step prevention handrail to protect the display

10- $\quad$ Security system (A new dimension in securing the building was added as the level of risk wasn't designed before to include explosion, it was just anti-theft. A new system was planned for heritage protection as follows):

- Supply and install infra-red cameras to capture by night

- Supply and install display screens for the monitoring system 
INTERNATIONAL JOURNAL OF

MULTIDISCIPLINARY STUDIES IN ARCHITECTURE

AND CULTURAL HERITAGE

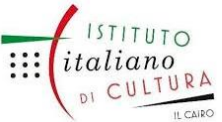

- Replace the fire alarm system and fire-fighting pumps

- Supply and install a tickets system and a metal detectors gate

- Supply and install revolving doors

- Maintain the sound system

- Upgrade security control panels

- Maintain all useful security systems from the previous conservation project

Another B.O.Q was also created as a supplementary phase to include the necessary items added to the project according to the stakeholders' vision. These items were not existent before in the 2002 conservation project and include: a gift shop, weapon and coin hall, glass doors, multimedia display systems and additional landscape work, among others.

In this research, Building Information Modeling was applied in its fourth and fifth dimensions by connecting the museum model to the time and cost museum schedule for the museum building and control room, excluding the administrative building and the museum garden. The added items in the second B.O.Q were not included in the experiment due to their location outside the museum building; except for the coin weapon and coin hall which was to be constructed inside.

\section{Managing Variables of The Additional Revitalization B.O.Q}

The additional work set in the second B.O.Q added a challenge with respect to re-scheduling the work stages. This work included the supply and installation of weapon and coin showcases for the new hall which carried the name of Emirati pilots who had died in concurrent a military mission. The hall was founded to keep their names alive; where graphic design was made for creating the labels and renewing the sign boards. Afterwards, the stakeholders decided to add the outdoor gift shop.

Multimedia devices were added as this technology wasn't used in the museum before, landscape features were also added to enhance the visual image of the museum garden and furniture for the restoration lab was 
INTERNATIONAL JOURNAL OF

MULTIDISCIPLINARY STUDIES IN ARCHITECTURE

AND CULTURAL HERITAGE

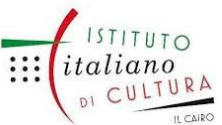

supplied because of the poor furniture that was used before. Out of these, only the weapon and coin hall was inscribed on the model created through BIM and a clash detection was reviewed to let the new items fit without implementation problems. The model was then dragged directly to Navisworks for linking aspects of time and cost.

12. Building Information Modeling for the Case Study

As mentioned, the methodology of the research takes the form of a joined research strategy combining both simulation and experimental approaches. Both approaches were followed in the case study where it started by simulation then the experiment of implementation through the support of BIM was initiated. these approaches can be summarized as follows:

\subsection{Simulation approach}

The simulation approach was taken to understand the expected future conditions through Building Information Modeling, as simulation is referred to as the operation of a numerical model that includes parameters and variables which can be developed according to work progressviii.

So the scenario of the research was: exploration, description, diagnosis, and experimentation, where BIM was used as a simulation strategy to manage the museum revitalization project in a much stressed time schedule and through tough political circumstances. The much information formulating the model was thus developed according to work progress. All the work was adjusted to reach the optimum design decision based on realistic cost estimates and time scheduling, with the ability to avoid collisions during the revitalization process of the predictive model created through BIM; especially since the fund value wasn't opt for change.

Project scope of work considered the variables and all the measurements taken from them and the model was developed according to work progress. Then after the additions, the cost was re- estimated without exceeding the fund budget. In 2002, the plan of the museum conservation and development of the exhibition design was approved, but in 2014 two main issues were affecting the proposed design. First, the lost objects which had to be replaced and, second; the weapon and coin new hall 
INTERNATIONAL JOURNAL OF

MULTIDISCIPLINARY STUDIES IN ARCHITECTURE

AND CULTURAL HERITAGE

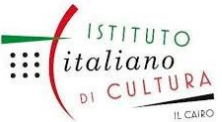

sponsor which the sponsor had asked to add on his behalf to register his participation, which needed to be included within the area of the museum and in the same time schedule. These were the main design problems which made a re-simulation of the model necessary to reach the best decisions in managing the project.

Using BIM in The Museum of Islamic Arts produced a dynamic simulation, where every stage of the implemented work could be reviewed in the model by moving through the time bar on the Navisworks software. It's beyond documentation and can be considered educational and marketing material since it can be recorded as a video or easily become a walkthrough product. Revit family was used for data entry in both 2D and 3D, the data of time and cost scheduling was originally planned through primavera and linked to the Revit model on Navisworks. This linked material helped in avoiding collisions in reality as the model predicts them in a clash detection outcome. Cost control was added by applying the 5D so the task of determining cash flow and releasing invoices became an easy one; since it's usually a monthly task in any management project.

While the simulation model is a product of reality, it simulated all the museum interiors even the objects inside the showcases where it can be a good marketing tool to show the museum collections and this model can be sold on an international scale. Also, the model was linked through the Google application to the real location so that the environmental data was reviewed and needed sun screens were added through Revit. Through these simulations, clashes were detected before happening which saved implementation time and money and effectively coordinated the architectural, electrical, mechanical, and security works.

As simulation is either iconic, analog, operational, or mathematical, the latter was the type used as it specifies being performed through a computer program that simulates reality by items that have numerical data, it even has a correlation with quantifiable valuesix. These values were saved in the file to be called for according to needed output, such as time scheduling or cost statistics or even clash detection, if existent. Since the project started through BIM, this gave us a predictive outcome for how the museum will end up like and it's already ended up as planned. 


\subsection{Experimental approach}

The purpose of the experiment is to measure the impact of using BIM on managing The Museum of Islamic Arts after the terrorist attack. As mentioned before, the items of implementation are considered the variables and the outcome from Revit and Navisworks are represented in the museum information modeling. When BIM simulates the building, LCM is done and all the significant variables are strongly observed along with the clashes and experiments of treatment whenever possible. The experiment started with the start of the implementation in January 2015 and can be summarized as follows:

1. Solar studies were applied to the model in Revit by displaying the sun path which provided a lot of information like natural lighting, shading, and potentials for passive solar design by offering locations for installing solar cells. Undesired sunlight near windows was spotted which could negatively affect the objects and the action taken was to apply steel meshes, see Fig. 2.

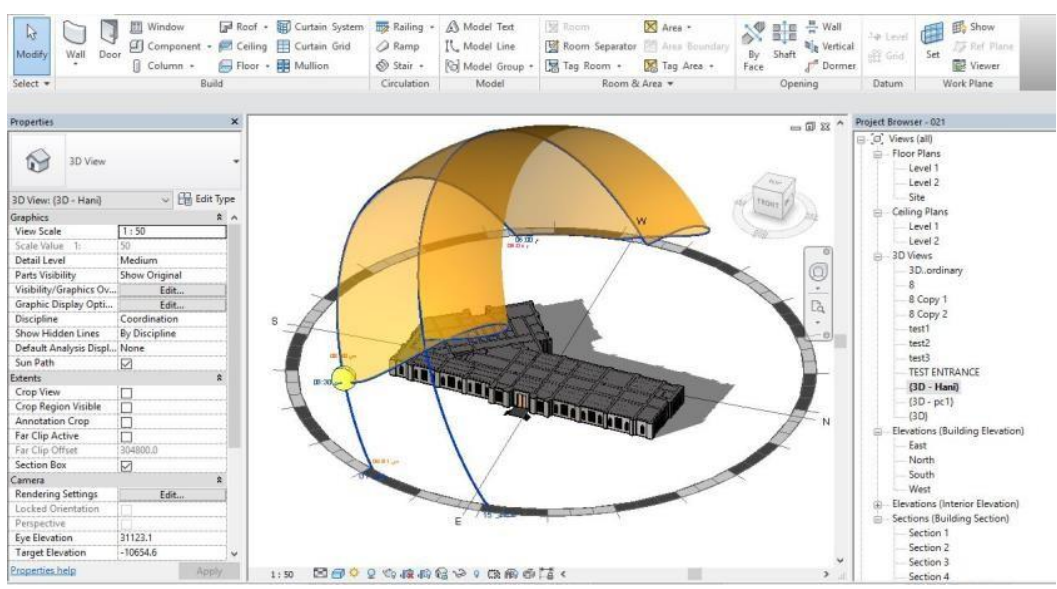

Fig. 2: Museum environmental studiesSource: Researcher 
INTERNATIONAL JOURNAL OF

MULTIDISCIPLINARY STUDIES IN ARCHITECTURE

AND CULTURAL HERITAGE

1. Setup for the project leveling in Revit was made as a start for themodel and as a base for the As Built drawing, followed by basic architectural elements from the site survey done by both Total Station and 3D Laser Scan, see Fig. 3

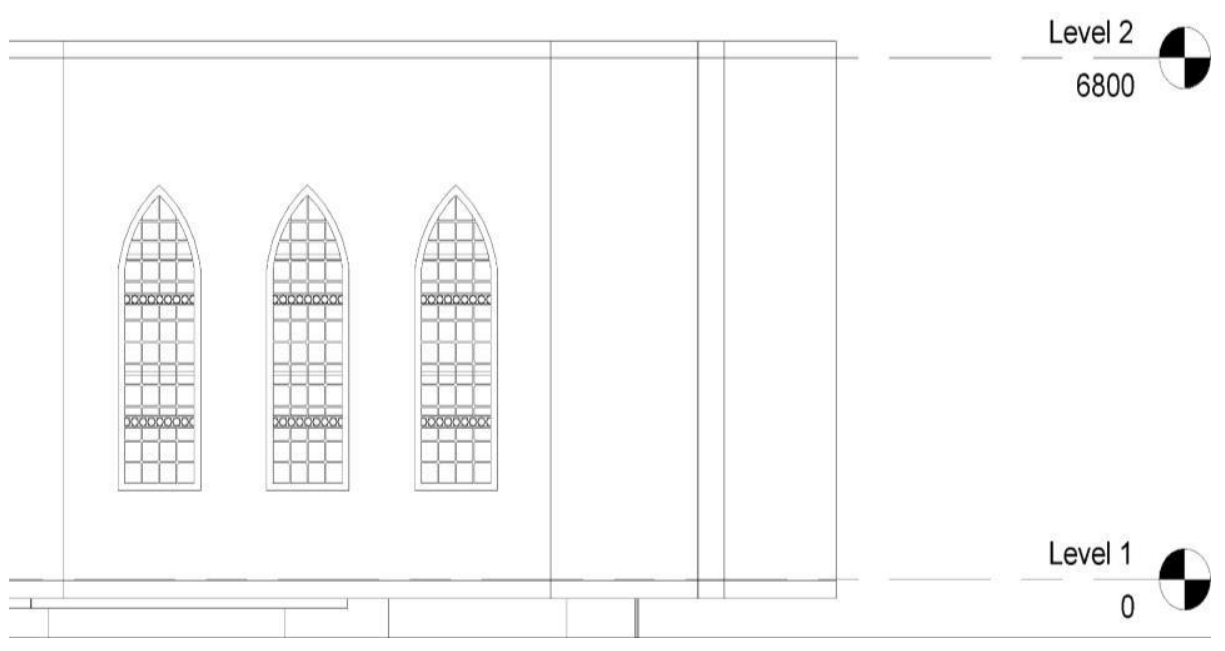

Fig. 3: Drawing data

entrySource:

Researcher

2. Flooring was added to the model, and architectural openings wereapplied to the walls in Revit.

3. All types of windows were added to the model:

4. Adding steel protection windows

5. Adding the aluminum windows

6. Adding the steel meshes

7. Stairs were added to the model in Revit

8. Layers of wall finishing were added in Revit

9. Showcases were added then the suspended ceiling and beamsdetails were added in Revit

10. The Revit model was exported as a NWC file extension andimported in Navisworks, see Fig. 4 

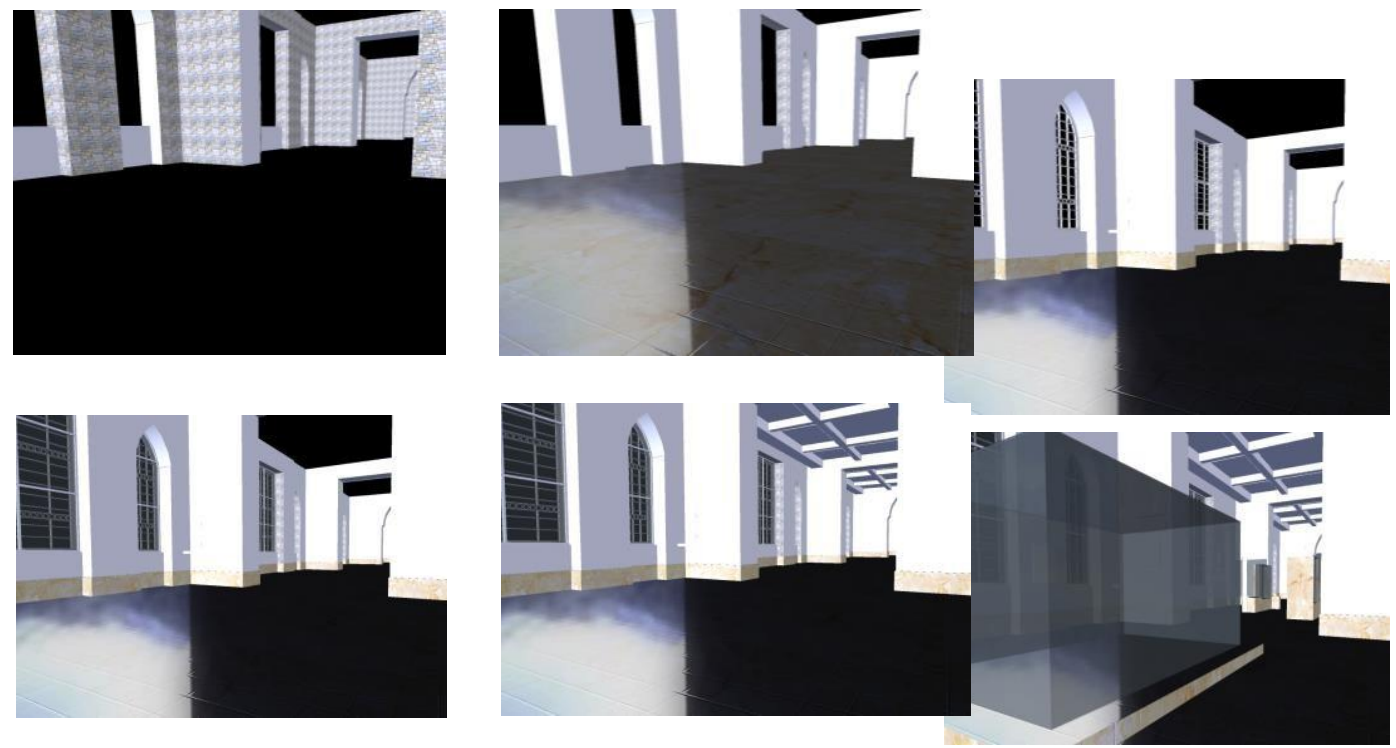

Fig. 4: Model imported in Navisworks showing work progress according to timeline Source: Researcher

11. Time schedule was exported from Primavera and imported inNavisworks

12. The model elements were linked with the time schedule according to each activity in Navisworks by picking all elements in the modelthat matched with each activity in the time schedule (4D Phase) 
13. The cost was added to each activity in the time schedule inNavisworks (5D Phase), see Fig. 5

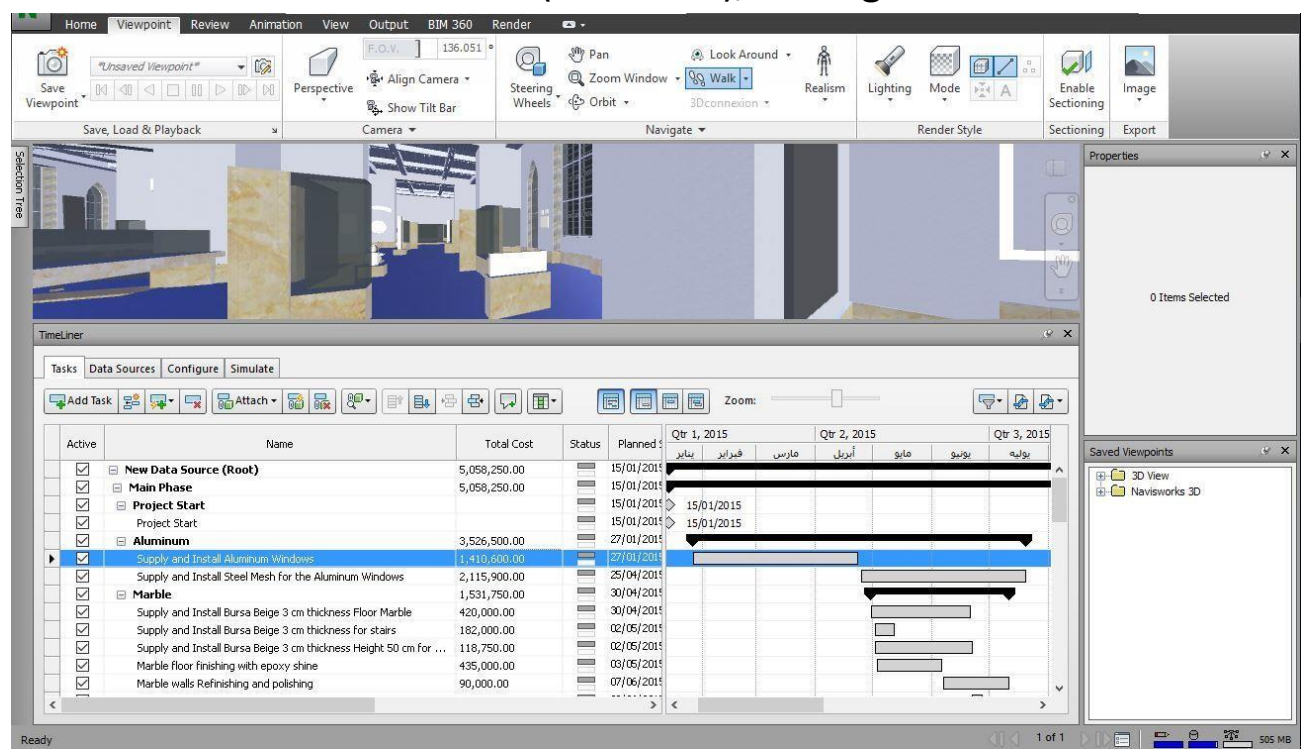

Fig. 5: Fourth and fifth dimensions applied to the museumthrough BIM

\section{Source: Researcher}

1. Navisworks clash detection was made, where all that was discovered was treated and considered in reality, which enabled performing interference checking to anticipate and manage potential problems in the Revit model and in the time schedule, seeFig. 6.
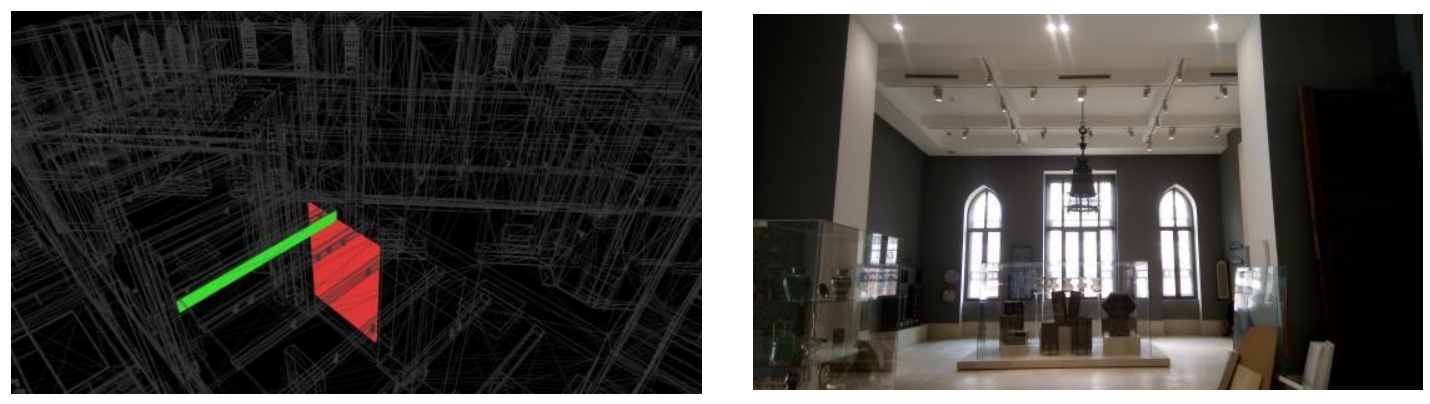

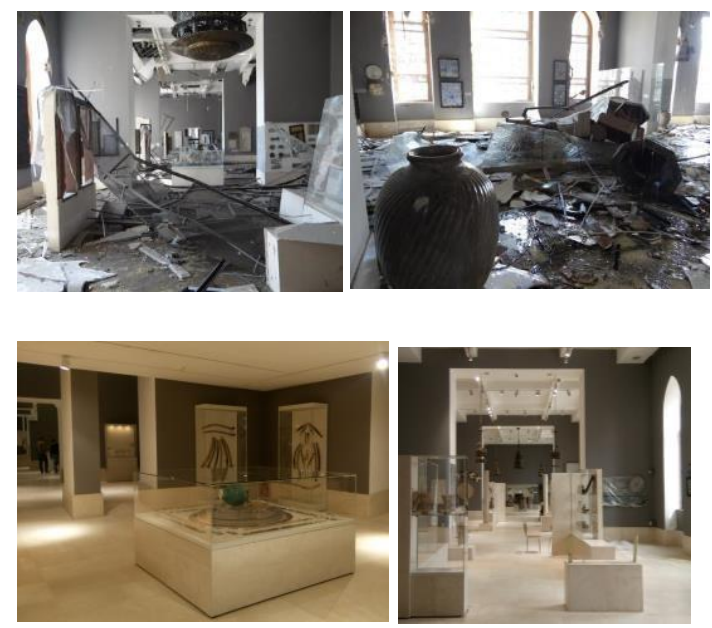

Fig. 6: Clash detection and the result in reality: Comparing before andafter finishing the project

Source: Researcher 2016

After fixing and rechecking clashes, the final model was modified and linked back to Navisworks. Fourth and fifth dimensions (Time scheduling - Cost evaluation) were applied to the museum model; where BIM kept the time and financial resources monitored all the time. BIM also helped in managing the crisis which made it a big challenge to finish the project in much less time than the 2002 conservation project. If this system was applied in heritage management, it will enhance performance in conservation and revitalization projects completely. In every project, the effort of human resources, time, money, and quality will be in control since every step is calculated and you can know all clashes before they even happen. In this experiment, cost was perfectly controlled and even with the additions and variations, the project cost and schedulewas still perfectly monitored and managed.

\section{Results}

When BIM was used, the efficiency increased compared to works divided between the software programs of drawing and management 
INTERNATIONAL JOURNAL OF

MULTIDISCIPLINARY STUDIES IN ARCHITECTURE

AND CULTURAL HERITAGE

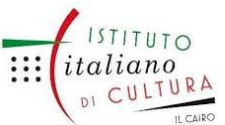

- $\quad$ Cost and time were saved when BIM was used when comparing time of implementation in 2002 and the revitalization project at 2015 as cost reduced for the same mentioned scope from $20 \%: 30 \%$, and time reduced from 24 month to 10 months

- Modeling has proven to be a positive tool for heritage marketing when planned through LOD from the beginning

- $\quad$ The software platform was easily modified by linking the files which is better than working on separate software programs

- $\quad$ time and human resources efforts saved while producing the cash flow and all resources reports together with Naviswork not to repeat the data entry in every software

- $\quad$ Clash detection in the major parts was useful in saving time and cost and achieving quality

- $\quad$ The model can be used through a new dimension; namely Facility Management

\section{Discussion and conclusion}

The hypothesis was built on that BIM can enable better management, and so testing procedures depended on management pillars which are time, money, and quality. Since quality in project management is not negotiable as a variable but is rather a constant, it was considered in both versions of the project before the terrorist attack and after.

Through LCM, some aspects - such as structural conservation works - which were considered in the 2002 project were not included in that of 2014 in order to enable focusing on the primary items of the new project. On the other hand, some aspects were added through the implementation such as the new weapon and coin showcases and the works done for the new gift shop. All uncommon items were included in the LCM and by comparing only the common items in both projects, it was highly registered that using BIM saved time and cost by predicting how the building would be like through the modeling process and connected information. The crisis factor made another challenge in adding a difficulty to the project implementation; especially in securing the objects in the beginning of the work, through all the previously mentioned procedures. Still the performance in time and cost was twice as less than the previous project which started in 2002 and was completed in 2010, while this project started in 2014 and was finished in 2016.

A huge database can be saved in BIM for historic buildings not only to be used within documentations of conservation and rehabilitation projects, but also for the application of the rest of BIM dimensions such as facility management which is known in the world of conservation as preventive conservation. The outcome model can even be used in marketing heritage by making walk-through movies which can be marketed through the website of the monument or 
INTERNATIONAL JOURNAL OF

MULTIDISCIPLINARY STUDIES IN ARCHITECTURE

AND CULTURAL HERITAGE

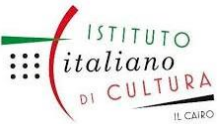

ISSN: $2735-4415$

VOLUME 1, ISSUE 2, 2018, 34 - 52.

www.egyptfuture.org/ojs/

even be sold as a DVD providing a virtual tour inside the museum. The model created through BIM in this project had better impact on managing heritage projects after a crisis for its efficiency in dealing with information and management procedures.

Since BIM changed the engineering thinking from visualization to simulation, BIM can also change the management of heritage in case of crisis to be an integrated approach for conservation, revitalization, and even preventive conservation.

It is strongly recommended to include BIM progress in its short, medium, and long terms of the management plan which is set by both the stakeholders and the government. It can combine documentation and a full plan including time and cost, then the maintenance program can be set through the dimension of facility management. BIM has successfully achieved better management in time of crisis when already everything has gotten complicated and needed more than ordinary management scheduling.

\section{References}

i Eastman, C. and others. BIM handbook: "A Guide to Building Information Modeling for Owners, Managers, Designers, Engineers and Contractors", Second Edition, John Wiley \& Sons, p.1.

ii Conover, D. and others, 2009. An introduction to Building Information Modelling (BIM). American Society of Heating, Refrigerating and AirConditioning Engineers, Inc. 1791, Tullie Circle,

N.E., Atlanta, Georgia 30329www.ashrae.org, p.

5.

iii Groat, L., Wang D., 2013. Architectural research methods, Wiley, p.125.

${ }^{\text {iv }}$ Louis, C., Manion, L., Morrison, K., 2007. Research methods ineducation, Sixth Edition, Routledge, p. 253.

${ }^{v}$ AIA, 2008. AIA Document E202 - 2008. Building Information Modeling Protocol Exhibit. http://www.fm.virginia.edu/fpc/ContractAdmin/ProfSvcs/BIMAI ASample.pdf (last visit: 22 February 2013).

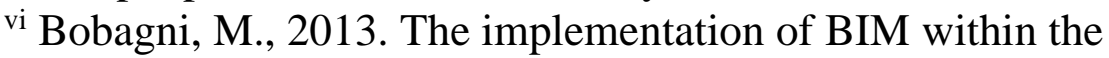
publicprocurement, VIT, p. 54. vii McNell, D. Building Information Modeling.http://community.infocomm.org 


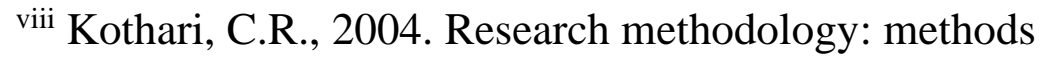
andtechniques.

${ }^{\text {ix }}$ Groat, L., Wang, D., 2013. Previous reference, Wiley, p. 360. 